When the Dark Shines:

The role of dark personality traits in leadership role occupancy and hiring decisions in a collectivistic culture

\author{
Siti Nuzulia \\ University of Hull
}

Felix Yong Peng Why

University of Hull 


\begin{abstract}
Two studies investigated the role of the Dark Triad traits (i.e., narcissism, psychopathy, and Machiavellianism), conscientiousness, and intelligence on leadership role occupancy and hiring decisions in Indonesian culture, which is a collectivist culture. Study 1 used Generalized Linear Model to examine two groups of participants with (i.e., school principals) and without (i.e., teachers) significant leadership responsibilities by controlling for participant grouping by school. The results indicated that, in comparison with teachers, school principals had significantly higher narcissism and conscientiousness and lower psychopathy and intelligence. In study 2, video recordings of simulated job interviews of 133 undergraduates were evaluated by 133 professional recruiters. Interviewee narcissism was the only significant positive predictor for hiring decision. Both studies provide consistent evidence that narcissism is a significant positive factor in both leadership role occupancy and hiring decision in a collectivist culture.
\end{abstract}

Keywords: Dark Triad traits, narcissism, leadership, hiring decisions, collectivistic culture 


\section{When the Dark Shines: The role of dark personality traits in leadership role occupancy and hiring decisions in a collectivistic culture}

The last two decades have seen growing interest in the role of the Dark Triad traits (i.e., narcissism, psychopathy, and Machiavellianism; Paulhus \& Williams, 2002) in occupational settings (LeBreton, Shiverdecker, \& Grimaldi, 2018). The increasing interest in the Dark Triad personality traits has examined its association with negative vocational outcomes, such as workplace deviance and counterproductive behaviours (Grijalva \& Newman, 2015; O'Boyle, Forsyth, Banks, \& McDaniel, 2012). However, despite these undesirable outcomes, some evidence indicates that individuals with Dark Triad characteristics are nonetheless still commonly recruited and given strategic roles in the workplace (Grijalva, Harms, Newman, Gaddis, \& Fraley, 2015; Jonason, Slomski, \& Partyka, 2012; Spurk, Keller, \& Hirschi, 2016). Unfortunately, limited studies have examined the Dark Triad traits’ impact on positive occupational outcomes (Grijalva et al., 2015; Spain, Harms, \& LeBreton, 2014; Spurk et al., 2016).

Most research on the Dark Triad traits has sampled American or European populations with individualistic cultures (Grijalva \& Newman, 2015; Santos, Varnum, \& Grossmann, 2017). Less research has examined the Dark Triad traits and career success in collectivistic societies in which harmony and group identity are central values (Markus \& Kitayama, 1991). In collectivistic cultures, Dark Triad characteristics (i.e., selfaggrandizement, willingness to manipulate, and emotional shallowness) are inconsistent with and violate the cultural norms of maintaining in-group membership, harmony, and cohesion and, hence, are sanctioned (Al-Jafary, Aziz, \& Hollingsworth, 1989; Kim, Chiu, Peng, Cai, \& Tov, 2009; O'Boyle et al., 2012; Stout, 2005). If such social censuring was significant, it would result in the Dark Triad traits having a weaker impact on career success in collectivist cultures. However, globalization has contributed to a general increase of individualism 
observed in collectivist cultures (Hamamura, 2012; Liu \& Wang, 2009; Santos et al., 2017), contributing to a generational increase of the Dark Triad traits. Therefore, an investigation on the Dark Triad traits' impact on occupational outcomes in collectivist cultures is warranted to improve cross-cultural generalizability of current research findings on this topic.

This paper seeks to integrate and extend limited existing findings regarding the impact of the Dark Triad traits on long-term positive occupational outcome (i.e., leadership role occupancy) and short-term positive occupational outcome (i.e., hiring decisions) in a collectivist culture. Many existing studies have examined the Dark Triad personality traits to positive occupational outcomes separately (e.g., Grijalva et al., 2015; Paulhus, Westlake, Calvez, \& Harms, 2013). But the dearth of studies that examine all three Dark Triad traits' simultaneously has resulted in a lack of information regarding which trait has the most impact (positive or negative) on these outcomes. Hence, a study including all Dark Triad traits offers an important conceptual contribution to this field of study.

The research also aims to replicate previous research on whether the traditional predictors (i.e., gender, conscientiousness, and intelligence) predict leadership role occupancy and hiring decisions (Carl, 2016; Egan, Daly, Delaney, Boyce, \& Wood, 2017; Marinova, Moon, \& Kamdar, 2013). To investigate these issues, we have conducted two studies in Indonesia, a collectivistic culture. Namely, we examined whether the Dark Triad personality traits predict leadership role occupancy (Study 1) and hiring decisions (Study 2). Study 1 used a cross-sectional design sampling school principals and teachers. Study 2 adopted a prospective quasi-experimental design to predict the hiring decisions made by human resource personnel based on videos of simulated job interviews of final-year undergraduates.

Among the Dark Triad traits, narcissism consistently positively predicts leadership selection (Grijalva et al., 2015; Higgins \& Judge, 2004) and hiring decision (Higgins \& Judge, 2004; Paulhus et al., 2013). Some research has noted that people high in narcissism 
who are confident, outgoing, charming, attractive, and entertaining (Goncalo, Flynn, \& Kim, 2010; Holtzman, Vazire, \& Mehl, 2010) are likely to emerge as leaders (Brunell et al., 2008; Grijalva et al., 2015; Harms, Spain, \& Hannah, 2011; Ong, Roberts, Arthur, Woodman, \& Akehurst, 2016; Paunonen, Lönnqvist, Verkasalo, Leikas, \& Nissinen, 2006). Moreover, Lindley (2018) has noted that those who are highly in narcissism are much more likely to be employed as managers. Paulhus et al. (2013) and Grijalva and Newman (2015) also have found that narcissism is a weaker but still significant predictor of positive occupational outcomes specifically among Asian participants. Hence, narcissism might be a significant predictor of leadership role occupancy even in collectivistic cultures. In terms of hiring decisions, limited studies have noted that individuals high in narcissism receive the most positive evaluations from interviewers (Back, Schmuckle, and Egloff, 2010; Paulhus et al., 2013), which could lead to a higher likelihood of success in acquiring a post after an interview. Narcissistic self-promoters were given higher rating for suitability for the job (Paulhus et al., 2013) and were considered better suited for managerial roles (Campbell, Hoffman, Campbell, \& Marchisio, 2011; Higgins \& Judge, 2004).

Conversely, there is also evidence that in the long term, narcissism will have negative consequences (O'Boyle et al., 2012; Ong et al., 2016). For instance, before initial group formation, narcissism was associated with positive peer-rated leadership; after group formation, the same association was negative (Ong et al., 2016). Meta-analyses have also reported that, in the long term, narcissism negatively relates to leadership effectiveness (Grijalva et al., 2015) and counterproductive behaviour (Grijalva \& Newman, 2015), because people with high narcissism often fail to maintain good interpersonal relationships with their co-workers (Morf \& Rhodewalt, 2001). Individuals high in narcissism also have mistrust towards and a lack of concern for others, create undesirable working environments, and engage in counterproductive behaviours (Morf \& Rhodewalt, 2001). Hence, some research 
suggests that narcissism predicts short-term career success but has long-term career detriments.

Hypothesis 1: Narcissism predicts (a) positive short-term occupational outcomes (i.e., hiring decisions) and (b) negative long-term occupational outcomes (i.e., leadership role occupancy).

While narcissism could be a positive predictor of short-term occupational outcomes in collectivist societies, psychopathy which is characterized by individuals who are without a conscience (Babiak \& Hare, 2007), has been found to be a negative predictor of job outcomes in various cultures (O'Boyle et al., 2012; Roulin \& Bourdage, 2017; Spain et al., 2014; Spurk et al., 2016). For example, Spurk et al. (2016) reported a negative relationship between psychopathy and leadership responsibilities. Harms et al. (2011) and O’Boyle et al. (2012) found that people high in psychopathy received fewer organizational rewards, such as promotions, and have less career success. Although research on psychopathy and hiring decisions is limited, some studies have found that interviewees who used deceptive impression management tactics, a behaviour commonly linked with psychopathy (Levashina \& Campion, 2006; Roulin \& Bourdage, 2017), received negative interview evaluations. Unfortunately, even experienced interviewers cannot properly identify when interviewees engage in deceptive impression management tactics (Levashina \& Champion, 2007; Roulin, Bangerter, \& Levashina, 2015). However, people high in psychopathy lack of regard for others may make them repulsive from the start and could even be an obstacle (Rauthmann, 2012; Rauthmann \& Kolar, 2012). Over a short period, new acquaintances (e.g., job interviewers) come to dislike people high in psychopathy more than they come to dislike individuals high in narcissism (Rauthmann \& Kolar, 2012). 
Arguably, there is some evidence to suggest that some characteristics of psychopathy, such as being charming and entertaining, might predict career success (Landay, Harms, \& Credé, 2019). For instance, a meta-analysis showed a positive, though weak, correlation between psychopathic tendencies and leadership emergence (Landay et al., 2019). Babiak, Neumann, and Hare (2010) and Boddy, Ladyshewsky, and Galvin (2010) found that individuals high in psychopathy were more likely to hold managerial positions. However, these studies did not examine the individualistic or collectivistic cultural background of their participants. Indeed, some characteristics of psychopathy, such as low empathy and erratic behaviour, contradict collectivist social values and are barriers to social acceptance (Babiak \& Hare, 2007), disadvantages them for their career success (Boddy et al., 2010). Hence, the current evidence supports a non-directional hypothesis between psychopathy and occupational outcomes.

Hypothesis 2: Psychopathy negatively predicts (a) long-term occupational outcomes and (b) short-term occupational outcome.

Machiavellianism, which refers to the manipulation of others without moral considerations (Becker \& Dan O'Hair, 2007), has negative connotations but contributes to career success (Ferris et al., 2005; Ng, Eby, Sorensen, \& Feldman, 2005). Studies have shown that Machiavellianism is beneficial for attaining leadership positions (Dahling, Whitaker, \& Levy, 2009; Spurk et al., 2016). People high in Machiavellianism are more likely to obtain their desired career choices (Dahling et al., 2009) and be hired in managerial positions (Lindley, 2018). Moreover, in a job interview, Hogue, Levashina, and Hang (2013) found that individuals high in Machiavellianism were more likely to use diverse tactics such as self-enhancement, image protection, and interpersonal manipulation to create a positive 
impression for the job interviewer, which might increase their chances of being hired for a job.

Nevertheless, these advantages of Machiavellianism are more often offset by important interpersonal hazards that frequently undermines relationships. For instance, Cohen (2018) described that individuals high in Machiavellianism start interactions with a friendly manner and yet can switch into hostile behaviours if this initial strategy does not help them to gain their objectives. People high in Machiavellianism have also been noted to act in a good behaviour which increases trust in others and subsequently change into deceptive tactics (i.e., lying, stealing, cheating, and misleading others) to maximize their personal advantages. Colleagues, subordinates, and supervisors gradually know the manipulative strategies employed by people high in Machiavellianism (O'Boyle et al., 2012). In a collectivistic culture where more work situations demand strong cooperative alliances with others, Machiavellianism is considered to violate this cultural norm (Al-Jafary, 1989). Furthermore, research has found that, in job interviews, Machiavellianism is related to dishonesty (Fletcher, 1990; Levashina \& Champion, 2006). This kind of deceptive impression management tactic leads to negative interview evaluations. Like psychopathy, even though people with high Machiavellianism manipulate job interviewers to make them more likeable, they are generally seen to be more disliked from the beginning (Rauthman, 2012).

Hypothesis 3: Machiavellianism negatively predicts (a) short-term occupational outcomes and (b) long-term occupational outcomes.

Additionally, according to research on 'traditional predictors' (i.e., conscientiousness and intelligence) of positive job outcomes, we hypothesize people with high conscientiousness have better hiring decisions and leadership occupancy because they are 
dutiful, highly motivated, and well organized (Marinova et al., 2013; Wiersma \& Kappe, 2017). Meanwhile, intelligence positively predicts leadership and better hiring decisions (Carl, 2016; Li, Dong, Arvey, \& Song, 2011) because it is associated with creative problem solving, learning, and handling uncertainties (Pulakos, Arad, Donovan, \& Plamondon, 2000). Previous research has also found that men are more likely to be hired and attain leadership roles (Carli \& Eagly, 2001).

Hypothesis 4: Gender, conscientiousness, and intelligence positively predict to longand short-term occupational outcomes.

\section{Study 1}

\section{Method}

Participants. Minimum target sample size was 203, assuming an effect size of $\mathrm{OR}=$ 1.80 (Grijalva et al., 2015), alpha $=.05$, and power $=.95$. A total of 479 Indonesians participated in this study, of which 274 were school principals (males $=244$, females $=30$ ) and 205 were teachers $($ males $=90$, females $=115$ ). All participants were civil servants from 297 Indonesian public schools. School principals were teachers who have met the minimum requirements of five years' relevant working experience, had nominated themselves for promotion to be principals and were subsequently appointed to be principals by a committee from the Indonesian Ministry of Education. The school principals were recruited from their Regional Annual Assessment Meeting held by the Indonesian Ministry of Education. The teachers were recruited from several public schools in Indonesia. Participant ages ranged from 27 to 59 years, Mean $(S D)=50.3$ (5.9) years, with work experience ranged from 7 to 36.1 years, Mean $(S D)=24.16(7.35)$ years. School principals and teachers were age matched to be within \pm 5 years. Leadership emergence was defined by participants who were school 
principals, who had significant leadership responsibilities, while school teachers had less leadership responsibilities.

Measures. The Short Dark Triad of Personality scale (SD3; Jones \& Paulhus, 2014) was used to measure the Dark Triad traits. Participants were asked how much they agreed or disagreed ( 1 = strongly disagree, 5 = strongly agree $)$ with each statement. Two independent translators translated and adapted the scale into Indonesian and verified it for accuracy using back translation. Conscientiousness was measured using nine items from the Big Five Inventory (BFI scale; John \& Srivastava, 1999). The BFI scale used in this study was the translated Indonesian version (Ramdhani, 2012). Participants were asked how much they agreed or disagreed $(1=$ strongly disagree, 5 = strongly agree $)$ with the statements. Raven's Advanced Progressive Matrices (Raven, Raven, \& Court, 1998) was used to measure fluid intelligence. It contains two sets of tests with a total of 48 items. The first set consisted of 12 items and the second set consisted of 36 items. We used the timed version for the second set.

Procedure. The participants were informed of the nature of the study, gave consent before completing the measures, and were debriefed at the end of their participation.

\section{Results and Discussion}

Table 1 includes descriptive statistics, intercorrelations, and maximal reliability (Li, Rosenthal, \& Rubin, 1996) for the variables. We tested the measurement model of the SD3 scale using IBM SPSS Amos 25. All 27 of the Dark Triad traits items loaded on three factors (see Figure 1). Measurement model fit indices showed a poor fit, $\chi^{2}(321, N=479)=917.98$, $p<.001 ; \mathrm{CFI}=.524, \mathrm{RMSEA}=.062$.

We performed generalized linear mixed model to analyse the data. The generalized linear mixed model had two levels. Level 1 was narcissism, psychopathy, Machiavellianism, conscientiousness, intelligence, and gender; level 2 was schools because some teachers 
worked in the same school. Result indicated that all predictors significantly differentiated between principals and teachers. Controlling for the effects of schools, results showed that narcissism, $\mathrm{b}(S E)=.712(0.246), p=.004, \mathrm{OR}=2.039,95 \%$ CI [1.258, 3.306], conscientiousness, $\mathrm{b}(S E)=.044(0.020), p=.031, \mathrm{OR}=1.045,95 \%$ CI $[1.004,1.087]$, and the male sex, $\mathrm{b}(S E)=1.767(0.242), p<.001, \mathrm{OR}=5.851,95 \%$ CI [3.637, 9.412], positively predicted leadership role occupancy. Meanwhile, psychopathy $\mathrm{b}(S E)=-.978(0.37), p=.009$, $\mathrm{OR}=0.376,95 \% \mathrm{CI}[0.182,0.779]$ and intelligence $\mathrm{b}(S E)=-.078(0.0295), p=.009, \mathrm{OR}=$ 0.925, 95\% CI [0.873, 0.981] negatively predicted leadership role occupancy. Machiavellianism did not predict leadership role occupancy $\mathrm{b}(S E)=.421(0.256), p=.101$, $\mathrm{OR}=1.524,95 \%$ CI $[0.921,2.520]$

The results indicated that narcissism, conscientiousness, and being male are positive predictors of leadership role occupancy while psychopathy and intelligence were negative predictors of leadership role occupancy. Machiavellianism was not a significant predictor. These findings support the role of narcissism on leadership in a collectivistic society. However, it contradicts previous research which found that narcissism predicts long-term career detriment. Consistent with previous research, psychopathy negatively predicted career success while conscientiousness was a positive predictor (Judge, Rodell, Klinger, Simon, \& Crawford, 2013; Sackett \& Walmsley, 2014). Contrary to previous research (Carl, 2016; Li, Dong, Arvey, \& Song, 2011), intelligence negatively predicted leadership role occupancy in our sample.

\section{Study 2}

\section{Method}

Participants. Participants were 113 final year Indonesian Psychology undergraduates. Forty-one (36\%) participants were male. Mean (SD) age was 21.4 (1.05) years. We recruited 
113 human resource recruiters from 78 different companies to assess the videotaped interviews. Sixty-one (54\%) professional human resources recruiters were male. The mean $(S D)$ age of these recruiters was 36.6 (8.5) years, and the Mean (SD) work experience was 8.2 (7.1) years. The recruiters worked in various sectors: banking (10.6 \%), health (2.65\%), hospitality (7.08\%), mining (3.54\%), consumer goods (14.2\%), education (26.5\%), construction (6.19\%), the military (7.96\%), and human resources (21.2\%). Grijalva and Newman's (2015) meta-analysis on narcissism and counterproductive work behaviours was used to estimate the effect size for our power calculations; using their corrected effect size, OR $=2.36(\rho=.23)$, alpha $=.05$, and power $=.95$, yielded a minimum $N$ of 100 .

Measures. As in Study 1, Narcissism and psychopathy were measured using the Bahasa Indonesian version of the Short Dark Traits scale (SD3; Jones \& Paulhus, 2014). Conscientiousness was measured using the Indonesian version (Ramdhani, 2012) of the Big Five Inventory (John \& Srivastava, 1999). The timed version of Raven's Advanced Progressive Matrices (APM; Raven, Raven, \& Court, 1998) measured fluid intelligence.

Procedures. Participants (interviewees) were informed that they would be interviewed by researchers to determine their potential to be hired as a human resources management trainee in a simulated job interview for an Indonesian company. They were also informed that the interview would be recorded with their informed consent and that this recording would be viewed by a professional human resources recruiter to make a hiring decision. Several days before the interview, participants completed the APM, SD3, and BFI. Each professional human resources recruiter was randomly allocated to assess the video recorded simulated interview of only one undergraduate interviewee. For each dyad, the undergraduate interviewee provided the predictor data (e.g., personality), while the recruiter provided the outcome data (i.e., hiring decision). On the interview day, the undergraduate participants were instructed to perform their best to impress the assessors during the 
interview sessions. The interview was conducted in a formal office with the interviewer behind a desk and the applicant in a facing chair. A video camera was positioned to record the participant in a relatively unobtrusive fashion. The interview procedure was standardized with a script. There was no time restriction for the interviews to allow the participant to complete all of the questions. The interview questions covered five essential job competencies (Spencer \& Spencer, 2008): achievement orientation (e.g., Tell me your success story as an undergraduate in your programme), interpersonal understanding (e.g., What did you think about others in [a specific situation]?), impact and influence (e.g., What did you do or say to others in [a specific situation]?), teamwork (e.g., Who was involved in [a specific situation]?), and self-confidence (e.g., How did you feel in [a specific situation] ?). The Mean $(S D)$ duration of the recorded interviews was 41.1(5.61) minutes.

\section{Results and Discussion}

Table 2 lists the means, standard deviations, and intercorrelations, and maximal reliability for the variables. Consistent with Study 1, Study 2 also has a poor measurement model fit for a three latent factor model for SD3, $\chi^{2}(321, N=113)=511.6, p<.001$, CFI $=.489$, RMSEA $=.073$ (see Figure 2).

We performed logistic regression which showed that out of the six predictors (i.e., narcissism, psychopathy, Machiavellianism, intelligence, conscientiousness, and gender), only narcissism was a significant predictor for hiring decision (Table 3). Classificatory analysis indicated that a total of $63.7 \%$ of all subjects were correctly classified.

The result was consistent with the hypothesis that narcissism can positively predict a person's success in hiring decisions. Meanwhile, Machiavellianism was borderline significant for negative hiring decisions. Psychopathy, intelligence, conscientiousness, and gender did not predict hiring decision. A finding in Study 2 that is consistent with Study 1 and previous 
studies is that narcissism is predicts positive occupational outcomes (Back, Schmukle, \& Egloff, 2010; Friedman, Oltmanns, Gleason, \& Turkheimer, 2006; Paulhus, 1998; Paulhus et al., 2013). Since a job interviewee's goal is to impress the interviewer or assessor, success may rest on an interviewee’s personality that helps build positive impressions (e.g., narcissism) rather than that associated with long-term performance (e.g., conscientiousness, intelligence; Paulhus et al., 2013).

\section{General Discussion}

We found that narcissism predicted leadership role occupancy (Study 1) and hiring decisions (Study 2). Conscientiousness and gender were positive predictors while psychopathy and intelligence were negative predictors for leadership role occupancy. The results for psychopathy, conscientiousness, intelligence, and gender did not consistently replicate across our two studies and Machiavellianism was consistently not a significant predictor for our studies. Our findings indicate that narcissism is an important predictor for leadership and hiring decisions not just for individualistic cultures but for a collectivist culture as well.

Our results showed that narcissism predicts both positive short-term (e.g., hiring decisions) and long-term occupational outcomes (e.g., leadership role occupancy). This contradicts previous research which suggested that narcissism has short-term occupational advantages but long-term disadvantages (Grijalva \& Newman, 2015; O'Boyle et al., 2012). Previous research found that narcissism is not related to better job performance (Grijalva et al., 2015) and is positively related to counterproductive work behaviours (Grijalva \& Newman, 2015). If true, this characteristic might culminate in poorer long-term career outcomes. However, narcissism in a collectivistic culture might manifest as self-enhancement for social connectedness rather than individuality. Individuals in individualistic cultures 
might emphasize their uniqueness and independence, whereas those in collectivistic cultures might emphasize their social connectedness and harmony (Grijalva \& Harms, 2014). A metaanalysis by Sedikides et al. (2005) found that people from individualistic cultures differentiated themselves from the in-group by focusing more on individualistic attributes (e.g., “I am more self-reliant than other community members”), whereas collectivist individuals emphasized more collectivistic attributes (e.g., "I am more loyal than other community members”). In this way, self-enhancement in collectivistic cultures can sustain and promote positive self-regard (Kurman, 2003; Sedikides et al., 2005) while simultaneously not contradicting a collectivist society’s virtues of modesty (Kurman, 2001; Kurman \& Sriram, 2002). Promoting themselves as competent in maintaining social harmony and group relationships might make individuals more suitable candidates for leadership or employment in collectivist cultures (Sedikides, Ntoumanis, \& Sheldon, 2018; Volmer, Koch, \& Göritz, 2017). Unfortunately, the SD3, used to assess narcissism in this paper, assesses whether individuals regard themselves as above average compared with others but do not specify in what domains/expertise they consider themselves above average in. Future research might examine further ways in which self-enhancement manifests in collectivist versus individual cultures, as people in different cultures might apply unique tactics to promote themselves (Grijalva \& Harms, 2014; Heine \& Hamamura, 2007; Kurman, 2001). Nonetheless, our study contributes to the limited research on narcissism's role in collectivistic cultures (Grijalva \& Newman, 2015; O'Boyle et al., 2012).

Some studies found that people high in narcissism exhibit a strong interest in being leaders early in their careers (Kowalski, Vernon, \& Schermer, 2017; Lindley, 2018), so they proactively seek such positions in organizations (Campbell \& Campbell, 2009). This interest is aided by their better hiring prospects during job interviews (Paulhus et al., 2013) in which, as replicated in our Study 2, participants high in narcissism tend to be evaluated more 
favourably (Schenure, 2010; Campbell \& Campbell, 2009). This could be why people high in narcissism are much more likely to be employed as managers (Lindley, 2018). Narcissism is particularly effective in leadership occupancy within the Indonesian educational setting as examined in Study 1. This is because in Indonesia, teachers put themselves forward for consideration to be promoted to school principals. This self-selection process opens itself for people high in narcissism to be school principals (Young \& Pinsky, 2006).

Our results indicate that narcissism can present another pathway for individuals to obtain the same positive career outcomes, even when their conscientiousness or intelligence is average or low. Someone with average or low intelligence can compensate by having another personal characteristic such as conscientiousness that is related to performance (Carroll, 1993). Likewise, some studies have shown that some individual difference attributes may compensate for low intelligence (Cote \& Miners, 2006; Moutafi, Furnham, \& Paltiel, 2004; Viswesvaran \& Ones, 2002). Intelligence negatively predicted leadership emergence in Study 1, but high narcissism might compensate for that trend. Narcissism's attributes, such as self-confidence, better performance in negotiations, lower stress and anxiety, upward career goals, and preference for jobs with greater responsibility, are beneficial for leadership attainment (Campbell et al., 2011; Judge \& LePine, 2007). This situation is often framed as the 'bright' or good side of narcissism (Hogan \& Kaiser, 2005).

The increasing acceptance of individualism in collectivist cultures could be another reason why narcissism predicts both short- and long-term career achievement. Research has reported a global trend towards the acceptance of individualism in collectivist cultures (Hamamura, 2012; Liu \& Wang, 2009; Santos et al., 2017). For instance, the younger generation in China endorses a stronger level of individualism values compared to the older generation (Liu \& Wang, 2009). Some studies have also noted that the frequency of words in books published in China indicating individualistic values (e.g., self, unique, personal, 
me/mine) has increased over time (Yu et al., 2016; Zeng \& Greenfield, 2015). If

individualistic values are gaining acceptance in collectivist cultures such as Indonesia, then employers may be more likely to view narcissistic self-enhancement as beneficial for job performance and less sanctioned in collectivist cultures than previously found.

Consistent with previous research, psychopathy negatively predicted long-term but not short-term careers (O'Boyle et al., 2012), and Machiavellianism did not predict either short- nor long-term career outcomes. One explanation for the inability of psychopathy and Machiavellianism to predict hiring decisions might be that psychopathy and Machiavellianism cannot be observed in a short duration 40 minutes job interview. In addition, Machiavellianism's impact on occupational outcomes might be nonlinear. For instance, for Zettler \& Solga’s (2013) inverse U-shape hypothesis of Machiavellianism, they reviewed research evidence for the association between Machiavellianism and better job outcomes only at low levels of this trait but at high levels of this trait, it is associated with poorer job outcomes.

Our two studies also found a poor fit for a three latent factor model for the SD3 scale. This finding is supported by Arseneault and Catano (2019) who tested the full SD3 construct in three different collectivist Asian countries and revealed a similar poor measurement model fit for SD3. However, though the SD3's internal psychometric structure did not appear to be that of three latent factors, convergent construct validity of this scale is replicated: the scores for SD3 correlated between narcissism and extraversion in a consistent way as reported by previous research (Douglas, Bore, \& Munro, 2012; Paulhus \& Williams, 2002; Veselka, Schermer, \& Vernon, 2012). In addition, internal psychometric structure of the SD3 is different from its predictive validity as well (Rosenthal \& Rosnow, 2008, p. 115). Thus, even though current research indicate that SD3 has an unclear internal psychometric structure, our studies and others reported elsewhere (e.g., LeBreton et al., 2018; O’Boyle, 2012; Palmer, 
Komarraju, Carter, \& Karau, 2017) has shown that it predicts occupational outcomes. That is, there is evidence for SD3's predictive utility. Nevertheless, cross-cultural consistency in the internal psychometric structure of SD3 still warrants further research. Perhaps behaviours assessed in SD3 that capture one personality characteristic in one culture might not capture the same personality characteristic in another culture (Arseneault \& Catano, 2019).

Some limitations of our research include its cross sectional design in Study 1, the overrepresentation of men (96.1\%) who were principals in Study 1, and the use of raw APM scores in both studies. Study 1's cross-sectional design restricted the inference of causality between the Dark Triad characteristics and career outcomes. However, Study 2 was prospective in design and provided some evidence for narcissism's potential causal role in positive occupational outcome. In addition, the gender disparity in Study 1 by principalteacher status was likely to be reflective of Indonesia’s sociocultural norms rather than sampling error. Indonesia has a patriarchal tradition in which men have more social and political power than women (Riantoputra \& Gatari, 2017). Hence, Indonesian men are more likely to be regarded and appointed as leaders (Carli \& Eagly, 2001). As for our use of raw APM scores as a measure of fluid intelligence, to our knowledge, there are no age-adjusted norms for Indonesians for APM to convert raw scores to percentile scores. Hence, we used the APM raw score. Using raw APM scores is unlikely to be problematic for our studies because in Study 1, teachers and school principals were matched for age. Hence, converting raw to age-adjusted APM scores will not impact on our group difference for this measure. For Study 2, participants were selected from a narrow age range (i.e., undergraduates), so ageadjusted norm scores would be unlikely to have a significant impact on our results.

Notwithstanding these limitations, our studies are the first to examine the Dark Triad personality traits, leadership role occupancy, and hiring decision in Indonesia. We found that narcissism predicts both short- (i.e., hiring decision) and long-term (i.e., leadership role 
occupancy) career achievements. We found that among the Dark Triad characteristics, Narcissism is the most consistent variable for predicting occupational outcomes, and that its predictive utility might also be relevant for collectivistic cultures such as Indonesia.

\section{Funding}

This research is based upon work fully supported by, Indonesian Endowment Fund (Lembaga Pengelola Dana Pendidikan-LPDP).

\section{Declaration of Conflicting Interests}

The authors declared no potential conflicts of interest with respect to the research, authorship, and/or publication of this article. 
Table 1

Descriptive statistic, zero-order correlations, point biserial correlation, $t$ values, and maximal reliability of the variables by Principal-Teacher group membership (Study 1), $N=479$

\begin{tabular}{|c|c|c|c|c|c|c|c|c|c|c|c|c|c|}
\hline & \multicolumn{2}{|c|}{ Mean $(S D)$} & \multirow[t]{2}{*}{2} & \multirow[t]{2}{*}{3} & \multirow[t]{2}{*}{4} & \multirow[t]{2}{*}{5} & \multirow[t]{2}{*}{6} & \multirow[t]{2}{*}{7} & \multirow[t]{2}{*}{8} & \multirow[t]{2}{*}{9} & \multirow[t]{2}{*}{10} & \multirow[t]{2}{*}{11} & \multirow[t]{2}{*}{$\rho \operatorname{Max}$} \\
\hline & $\begin{array}{l}\text { Principal } \\
(n=274)\end{array}$ & $\begin{array}{c}\text { Teacher } \\
(n=205)\end{array}$ & & & & & & & & & & & \\
\hline 1. Narcissism & $2.9(0.51)$ & $2.7(0.42) * *$ & $.191^{* *}$ & $.278 * *$ & $.274 * *$ & $-.205 * *$ & $.267 * *$ & $.369 * *$ & $.179 * *$ & .085 & $.213^{* *}$ & $.130 * *$ & 0.655 \\
\hline 2. Psychopathy & $2.0(0.34)$ & $2.1(0.35)$ & - & $.144^{* *}$ & $-.221 * *$ & $.213^{* *}$ & $-.121 * *$ & .026 & $-.254 * *$ & .023 & -.075 & .074 & 0.629 \\
\hline 3. Machiavellianism & $3.2(0.43)$ & $3.1(0.47) *$ & & - & -.014 & $.099 *$ & -.068 & -.028 & -.045 & -.013 & $.090 *$ & .008 & 0.505 \\
\hline 4. Conscientiousness & 36.4 (3.3) & $34.6(4.2) *$ & & & - & $-.579 * *$ & $.575 * *$ & $.497 * *$ & $.577 * *$ & -.062 & $.222 * *$ & $.130 * *$ & 0.889 \\
\hline 5. Neuroticism & 17.9 (3.9) & $19.3(4.2) * *$ & & & & - & $-.577 * *$ & $-.396 * *$ & $-.461 * *$ & .057 & $-.162 * *$ & $-.192 * *$ & 0.822 \\
\hline 6. Extraversion & $30.9(3.4)$ & $30.1(3.7) *$ & & & & & - & $.468 * *$ & $.541^{* *}$ & -.081 & $.116 *$ & $.103^{*}$ & 0.806 \\
\hline 7. Openness & 35.7 (3.6) & $34.6(3.9) * *$ & & & & & & - & $.337 * *$ & .056 & $.142^{* *}$ & $.157 * *$ & 0.849 \\
\hline 8. Agreeableness & $37.8(3.7)$ & 37.2 (3.6) & & & & & & & - & .055 & .087 & .009 & 0.879 \\
\hline 9. IQ, Raven’s & $8.6(2.4)$ & $10.8(6.6) * *$ & & & & & & & & - & $-.237 * *$ & $-.217 * *$ & \\
\hline 10. Position ${ }^{\mathrm{a}}$ & & & & & & & & & & & - & $486 * *$ & \\
\hline 11. Gender ${ }^{b}$ & & & & & & & & & & & & - & \\
\hline
\end{tabular}

11. Gender

${ }^{*} p<.05 . * * p<.01$

aTeachers were coded as ' 0 ' and Principals were coded as ' 1 '

${ }^{\mathrm{b}}$ Male $=1$, Female $=0$

$\rho$ Max $=$ Maximal Reliability 
Table 2

Descriptive statistic, zero-order correlations, point biserial correlation, $t$ values, and maximal reliability of the variables by Hiring recommendation group (Study 2 ), $N=$ 113

\begin{tabular}{|c|c|c|c|c|c|c|c|c|c|c|c|c|c|}
\hline & \multicolumn{2}{|c|}{ Mean $(S D)$} & \multirow[t]{2}{*}{2} & \multirow[t]{2}{*}{3} & \multirow[t]{2}{*}{4} & \multirow[t]{2}{*}{5} & \multirow[t]{2}{*}{6} & \multirow[t]{2}{*}{7} & \multirow[t]{2}{*}{8} & \multirow[t]{2}{*}{9} & \multirow[t]{2}{*}{10} & \multirow[t]{2}{*}{11} & \multirow[t]{2}{*}{$\rho \operatorname{Max}$} \\
\hline & $\begin{array}{c}\text { Hire } \\
(n=41)\end{array}$ & $\begin{array}{l}\text { Not Hire } \\
(n=72)\end{array}$ & & & & & & & & & & & \\
\hline 1. Narcissism & $3.3(0.42)$ & $3.0(0.51)^{*}$ & $.204 *$ & .082 & .070 & .053 & $.356 * *$ & .130 & -.116 & -.094 & $.224 *$ & -.054 & 0.713 \\
\hline 2. Psychopathy & $2.4(0.39)$ & $2.4(0.35)$ & - & $.322 * *$ & -.118 & .092 & -.027 & $.189 *$ & $-.297 * *$ & .069 & .032 & $-.297 * *$ & 0.579 \\
\hline 3. Machiavellianism & $3.5(0.44)$ & $3.6(0.41)$ & & - & -.096 & .154 & .032 & .024 & -.061 & -.111 & -.157 & -.060 & 0.551 \\
\hline 4. Conscientiousness & $30.7(4.2)$ & $30.9(4.13)$ & & & - & $-3.41 * *$ & .096 & -.035 & $.255^{* *}$ & -.049 & -.022 & -.045 & 0.778 \\
\hline 5. Neuroticism & $23.4(4.7)$ & $22.9(4.7)$ & & & & - & $-.197 *$ & -.149 & $-.291 * *$ & -.136 & .059 & $.195 *$ & 0.725 \\
\hline 6. Extraversion & $28.5(4.1)$ & 27.7 (4.63) & & & & & - & $.347 * *$ & $.282^{* *}$ & $-.274^{* *}$ & .079 & -.037 & 0.813 \\
\hline 7. Openness & $35.8(4.2)$ & $36.0(5.00)$ & & & & & & - & .048 & -.070 & -.028 & $-.243^{* *}$ & 0.831 \\
\hline 8. Agreeableness & $34.3(3.8)$ & $34.9(3.75)$ & & & & & & & - & $-.306 * *$ & -.076 & .095 & 0.789 \\
\hline 9. IQ, Raven’s & $20.0(5.22)$ & $19.9(6.05)$ & & & & & & & & - & .010 & $-.223^{*}$ & \\
\hline 10. Recommendation ${ }^{\mathrm{a}}$ & & & & & & & & & & & - & -.005 & \\
\hline 11. Gender ${ }^{\mathrm{b}}$ & & & & & & & & & & & & - & \\
\hline
\end{tabular}

$* p<05 * * p<01$

aNot hire were coded as ' 0 ' and hire were coded as ' 1 '

${ }^{\mathrm{b}}$ Male $=1$, Female $=0$

$\rho$ Max $=$ Maximal Reliability 
Table 3

Logistic regression predicting hired decision

\begin{tabular}{lcccc}
\hline \multicolumn{1}{c}{ Predictors } & $\mathrm{b}(S E)$ & $\begin{array}{c}\text { Wald chi- } \\
\text { squared }\end{array}$ & $p$ & OR, 95\% CI \\
\hline Narcissism & $1.113(0.460)$ & 5.856 & .016 & $3.043[1.236,7.496]$ \\
Psychopathy & $0.276(0.633)$ & 0.191 & .662 & $1.318[0.381,4.559]$ \\
Machiavellianism & $-1.023(0.523)$ & 3.822 & .051 & $0.360[0.129,1.003]$ \\
Conscientiousness & $-0.028(0.051)$ & 0.308 & .579 & $0.972[0.880,1.074]$ \\
Intelligence & $0.002(0.038)$ & 0.004 & .951 & $1.002[0.931,1.079]$ \\
Gender & $-0.076(0.465)$ & 0.027 & .870 & $0.926[0.372,2.307]$ \\
\hline
\end{tabular}

Note. $R^{2}=.086$ (Cox \& Snell), .118 (Nagelkerke), $\chi^{2}(8, N=113)=6.469, p>.05$ (Hosmer \& Lemeshow) 


\section{References}

Al-Jafary, A. A., Aziz, A., \& Hollingsworth, A. T. (1989). Leadership styles, Machiavellianism, and needs of Saudi Arabian managers. International Journal of Value-Based Management, 2(1), 103-111. doi:10.1007/bf01714974

Arseneault, R., \& Catano, V. (2019). An extension of the dark triad and five-factor model to three Asian societies. Asian Journal of Social Psychology. Advance online publication. doi:10.1111/ajsp.12378

Babiak, P., \& Hare, R. D. (2007). Snakes in suits. New York: HarperCollins.

Babiak, P., Neumann, C. S., \& Hare, R. D. (2010). Corporate psychopathy: Talking the walk. Behavioral Sciences \& the Law, 28(2), 174-193. doi:10.1002/bsl.925

Back, M. D., Schmukle, S. C., \& Egloff, B. (2010). Why are narcissists so charming at first sight? Decoding the narcissism-popularity link at zero acquaintance. Journal of Personality and Social Psychology, 98(1), 132-145. doi:10.1037/a0016338

Becker, J. A., \& Dan O'Hair, H. (2007). Machiavellians’ motives in organizational citizenship behavior. Journal of Applied Communication Research, 35(3), 246-267. doi:10.1080/00909880701434232

Boddy, C. R. P., Ladyshewsky, R., \& Galvin, P. (2010). Leaders without ethics in global business: Corporate psychopaths. Journal of Public Affairs, 10(3), 121-138. doi:10.1002/pa.352

Brunell, A. B., Gentry, W. A., Campbell, W. K., Hoffman, B. J., Kuhnert, K. W., \& DeMarree, K. G. (2008). Leader emergence: The case of the narcissistic leader. Personality and Social Psychology Bulletin, 34(12), 1663-1676. doi:10.1177/0146167208324101

Campbell, W. K., \& Campbell, S. M. (2009). On the self-regulatory dynamics created by the peculiar benefits and costs of narcissism: A contextual reinforcement model and 
examination of leadership. Self and Identity, 8(2-3), 214-232. doi:10.1080/15298860802505129

Campbell, W. K., Hoffman, B. J., Campbell, S. M., \& Marchisio, G. (2011). Narcissism in organizational contexts. Human resource management review, 21(4), 268-284.

Carl, N. (2016). IQ and socio-economic development across local authorities of the UK. Intelligence, 55, 90-94. doi:10.1016/j.intell.2016.02.001

Carli, L. L., \& Eagly, A. H. (2001). Gender, hierarchy, and leadership: An introduction. Journal of Social issues, 57(4), 629-636. doi: 10.1111/0022-4537.00232

Carroll, J. B. (1993). Human cognitive abilities: A survey of factor-analytic studies. Cambridge, UK: Cambridge University Press.

Cohen, A. (2018). Counterproductive work behaviors. Understanding the dark side of personalities in organizational life. New York: Routledge

Cote, S., \& Miners, C. T. (2006). Emotional intelligence, cognitive intelligence, and job performance. Administrative Science Quarterly, 51(1), 1-28. doi: 10.2189/asqu.51.1.1

Dahling, J. J., Whitaker, B. G., \& Levy, P. E. (2009). The development and validation of a new Machiavellianism scale. Journal of management, 35(2), 219-257. doi:10.1177/0149206308318618

Douglas, H., Bore, M., \& Munro, D. (2012). Distinguishing the dark triad: Evidence from the five-factor model and the Hogan development survey. Psychology, 3(3), 237-242. doi:10.4236/psych.2012.33033

Egan, M., Daly, M., Delaney, L., Boyce, C. J., \& Wood, A. M. (2017). Adolescent conscientiousness predicts lower lifetime unemployment. Journal of applied psychology, 102(4), 700-709. doi:10.1037/apl0000167 
Ferris, G. R., Treadway, D. C., Kolodinsky, R. W., Hochwarter, W. A., Kacmar, C. J., Douglas, C., \& Frink, D. D. (2005). Development and validation of the political skill inventory. Journal of management, 31(1), 126-152. doi:10.1177/0149206304271386

Fletcher, C. (1990). The relationships between candidate personality, self-presentation strategies, and interviewer assessments in selection interviews: An empirical study. Human Relations, 43(8), 739-749. doi:10.1177/001872679004300803

Friedman, J. N., Oltmanns, T. F., Gleason, M. E., \& Turkheimer, E. (2006). Mixed impressions: Reactions of strangers to people with pathological personality traits. Journal of Research in Personality, 40(4), 395-410. doi:10.1016/j.jrp.2005.01.005

Goncalo, J. A., Flynn, F. J., \& Kim, S. H. (2010). From a mirage to an oasis: Narcissism, perceived creativity and creative performance. Academy of Management Proceedings, New York, 1, 1-6. doi: 10.5465/ambpp.2010.54496125

Grijalva, E., \& Harms, P., D. (2014). Narcissism: An integrative synthesis and dominance complementarity model. Academy of Management Perspectives, 28(2), 108-127. doi:10.5465/amp.2012.0048

Grijalva, E., Harms, P. D., Newman, D. A., Gaddis, B. H., \& Fraley, R. C. (2015). Narcissism and leadership: A meta-analytic review of linear and nonlinear relationships. Personnel Psychology, 68(1), 1-47. doi:10.1111/peps.12072

Grijalva, E., \& Newman, D. A. (2015). Narcissism and counterproductive work behavior (CWB): Meta-analysis and consideration of collectivist culture, Big Five personality, and narcissism's facet structure. Applied Psychology, 64(1), 93-126. doi: 10.1111/apps.12025

Hamamura, T. (2012). Are cultures becoming individualistic? A cross-temporal comparison of individualism-collectivism in the United States and Japan. Personality and Social Psychology Review, 16(1), 3-24. doi:10.1177/1088868311411587 
Harms, P. D., Spain, S. M., \& Hannah, S. T. (2011). Leader development and the dark side of personality. The leadership quarterly, 22(3), 495-509. doi:10.1016/j.leaqua.2011.04.007

Heine, S. J., \& Hamamura, T. (2007). In search of East Asian self-enhancement. Personality and Social Psychology Review, 11(1), 4-27. doi:10.1177/1088868306294587

Higgins, C. A., \& Judge, T. A. (2004). The effect of applicant influence tactics on recruiter perceptions of fit and hiring recommendations: A field study. Journal of applied psychology, 89(4), 622-632. doi:10.1037/0021-9010.89.4.622

Hogan, R., \& Kaiser, R. B. (2005). What we know about leadership. Review of general psychology, 9(2), 169-180. doi:10.1037/1089-2680.9.2.169

Hogue, M., Levashina, J., \& Hang, H. (2013). Will I fake it? The interplay of gender, Machiavellianism, and self-monitoring on strategies for honesty in job interviews. Journal of business ethics, 117(2), 399-411. doi:10.1007/s10551-012-1525-x

Holtzman, N. S., Vazire, S., \& Mehl, M. R. (2010). Sounds like a narcissist: Behavioral manifestations of narcissism in everyday life. Journal of Research in Personality, 44(4), 478-484. doi:10.1016/j.jrp.2010.06.001

Jonason, P. K., Slomski, S., \& Partyka, J. (2012). The Dark Triad at work: How toxic employees get their way. Personality and Individual Differences, 52(3), 449-453. doi:10.1016/j.paid.2011.11.008

Jones, D., N, \& Paulhus, D., L. (2014). Introducing the short dark triad (SD3) a brief measure of dark personality traits. Assessment, 21(1), 28-41. doi:10.1177/1073191113514105

Judge, T. A., \& LePine, J. A. (2007). The bright and dark sides of personality: Implications for personnel selection in individual and team contexts. In Langan-Fox, J., Cooper, L. C., \& Klimoski, J. R (Eds.), Research Companion to the Dysfunctional 
Workplace: Management Challenges and Symptoms (pp. 332-355). Cheltenham, UK: Edward Elgar Publishing Ltd.

Judge, T. A., Rodell, J. B., Klinger, R. L., Simon, L. S., \& Crawford, E. R. (2013). Hierarchical representations of the five-factor model of personality in predicting job performance: integrating three organizing frameworks with two theoretical perspectives. Journal of applied psychology, 98(6), 875-925. doi:10.1037/a0033901

Kim, Y. H., Chiu, C.Y., Peng, S., Cai, H., \& Tov, W. (2009). Explaining East-West differences in the likelihood of making favorable self-evaluations: The role of evaluation apprehension and directness of expression. Journal of Cross-Cultural Psychology, 41(1), 62-75. doi:10.1177/0022022109348921

Kowalski, C. M., Vernon, P. A., \& Schermer, J. A. (2017). Vocational interests and dark personality: Are there dark career choices? Personality and Individual Differences, 104, 43-47. doi:10.1016/j.paid.2016.07.029

Kurman, J. (2001). Self-enhancement: Is it restricted to individualistic cultures?. Personality and Social Psychology Bulletin, 27(12), 1705-1716. doi:10.1177/01461672012712013

Kurman, J. (2003). Why is self-enhancement low in certain collectivist cultures? An investigation of two competing explanations. Journal of Cross-Cultural Psychology, 34(5), 496-510. doi:10.1177/0022022103256474

Kurman, J., \& Sriram, N. (2002). Interrelationships among vertical and horizontal collectivism, modesty, and self-enhancement. Journal of Cross-Cultural Psychology, 33(1), 71-86. doi:10.1177/0022022102033001005

Landay, K., Harms, P., \& Credé, M. (2019). Shall we serve the dark lords? A meta-analytic review of psychopathy and leadership. Journal of applied psychology, 104(1), 183196. doi:10.1037/apl0000357 
LeBreton, J. M., Shiverdecker, L. K., \& Grimaldi, E. M. (2018). The Dark Triad and workplace behavior. Annual Review of Organizational Psychology and Organizational Behavior, 5, 387-414. doi:10.1146/annurev-orgpsych-032117104451

Levashina, J., \& Campion, M. A. (2006). A model of faking likelihood in the employment interview. International Journal of Selection and Assessment, 14(4), 299-316. doi:10.1111/j.1468-2389.2006.00353.x

Li, H., Rosenthal, R., \& Rubin, D. B. (1996). Reliability of measurement in psychology: From Spearman-Brown to maximal reliability. Psychological Methods, 1(1), 98-107. doi:10.1037/1082-989X.1.1.98

Li, W. D., Arvey, R. D., \& Song, Z. (2011). The influence of general mental ability, selfesteem and family socioeconomic status on leadership role occupancy and leader advancement: The moderating role of gender. The leadership quarterly, 22(3), 520534. doi:10.1016/j.leaqua.2011.04.009

Lindley, J. K. (2018). Are there unexplained financial rewards for the snakes in suits? A labour market analysis of the Dark Triad of personality. British Journal of Industrial Relations, 56(4), 770-797. doi:10.1111/bjir.12269

Liu, C., \& Wang, S. (2009). Transformation of Chinese cultural values in the era of globalization: Individualism and Chinese youth. Intercultural Communication Studies, 18(2), 54-71.

Marinova, S. V., Moon, H., \& Kamdar, D. (2013). Getting ahead or getting along? The twofacet conceptualization of conscientiousness and leadership emergence. Organization Science, 24(4), 1257-1276. doi:10.1287/orsc.1120.0781 
Markus, H. R., \& Kitayama, S. (1991). Culture and the self: Implications for cognition, emotion, and motivation. Psychological review, 98(2), 224-253. doi:10.1037\%2F0033-295X.98.2.224

Morf, C. C., \& Rhodewalt, F. (2001). Unravelling the paradoxes of narcissism: A dynamic self-regulatory processing model. Psychological Inquiry, 12(4), 177-196. doi:10.1207/S15327965PLI1204_1

Moutafi, J., Furnham, A., \& Paltiel, L. (2004). Why is conscientiousness negatively correlated with intelligence?. Personality and Individual Differences, 37(5), 10131022. doi:10.1016/j.paid.2003.11.010

Ng, T. W., Eby, L. T., Sorensen, K. L., \& Feldman, D. C. (2005). Predictors of objective and subjective career success: A meta-analysis. Personnel Psychology, 58(2), 367-408. doi:10.1111/j.1744-6570.2005.00515.x

O'Boyle, E. H., Forsyth, D. R., Banks, G. C., \& McDaniel, M. A. (2012). A meta-analysis of the Dark Triad and work behavior: A social exchange perspective. Journal of applied psychology, 97(3), 557-579. doi:10.1037/a0025679

Ong, C. W., Roberts, R., Arthur, C. A., Woodman, T., \& Akehurst, S. (2016). The leader ship is sinking: A temporal investigation of narcissistic leadership. Journal of Personality, 84(2), 237-247. doi:10.1111/jopy.12155

Palmer, J. C., Komarraju, M., Carter, M. Z., \& Karau, S. J. (2017). Angel on one shoulder: Can perceived organizational support moderate the relationship between the Dark Triad traits and counterproductive work behavior?. Personality and Individual Differences, 110, 31-37. doi: 10.1016/j.paid.2017.01.018

Paulhus, D. L. (1998). Interpersonal and intrapsychic adaptiveness of trait self-enhancement: A mixed blessing?. Journal of Personality and Social Psychology, 74(5), 1197-1208. doi:10.1037/0022-3514.74.5.1197 
Paulhus, D. L., Westlake, B. G., Calvez, S. S., \& Harms, P. D. (2013). Self-presentation style in job interviews: The role of personality and culture. Journal of applied social psychology, 43(10), 2042-2059. doi:10.1111/jasp.12157

Paulhus, D. L., \& Williams, K. M. (2002). The dark triad of personality: Narcissism, Machiavellianism, and psychopathy. Journal of Research in Personality, 36(6), 556563. doi:10.1016/S0092-6566(02)00505-6

Paunonen, S. V., Lönnqvist, J. E., Verkasalo, M., Leikas, S., \& Nissinen, V. (2006). Narcissism and emergent leadership in military cadets. The leadership quarterly, 17(5), 475-486. doi:10.1016/j.leaqua.2006.06.003

Pulakos, E. D., Arad, S., Donovan, M. A., \& Plamondon, K. E. (2000). Adaptability in the workplace: Development of a taxonomy of adaptive performance. Journal of applied psychology, 85(4), 612-624. doi:10.1037/0021-9010.85.4.612

Rauthmann, J. F. (2012). The Dark Triad and interpersonal perception: Similarities and differences in the social consequences of narcissism, Machiavellianism, and psychopathy. Social psychological and personality science, 3(4), 487-496. doi:10.1177/1948550611427608

Rauthmann, J. F., \& Kolar, G. P. (2012). How “dark” are the Dark Triad traits? Examining the perceived darkness of narcissism, Machiavellianism, and psychopathy. Personality and Individual Differences, 53(7), 884-889. doi:10.1016/j.paid.2012.06.020

Raven, J, R., Raven, J. C., \& Court, J. H. (1998). Advanced progressive matrices. San Antonio, TX: NCS Pearson Inc.

Riantoputra, C. D., \& Gatari, E. (2017). Women leaders in Indonesia: Current picture and strategies for empowerment. In Cho, Y., Ghosh, R., Sun, J. Y., \& McLean, N. G 
(Eds.), Current Perspectives on Asian Women in Leadership: A Cross-Cultural Analysis (pp. 55-70). Cham: Springer International Publishing.

Rosental, R., \& Rosnow, L. R. (2008). Essentials of behavioural research. Methods and data analysis. Boston: McGraw-Hill.

Roulin, N., Bangerter, A., \& Levashina, J. (2015). Honest and deceptive impression management in the employment interview: Can it be detected and how does it impact evaluations? Personnel Psychology, 68(2), 395-444. doi:10.1111/peps.12079

Roulin, N., \& Bourdage, J. S. (2017). Once an impression manager, always an impression manager? Antecedents of honest and deceptive impression management use and variability across multiple job interviews. Frontiers in psychology, 8(29). 1-13. doi:10.3389/fpsyg.2017.00029

Sackett, P. R., \& Walmsley, P. T. (2014). Which personality attributes are most important in the workplace? Perspectives on Psychological Science, 9(5), 538-551. doi:10.1177/1745691614543972

Santos, H. C., Varnum, M. E. W., \& Grossmann, I. (2017). Global increases in individualism. Psychological Science, 28(9), 1228-1239. doi:10.1177/0956797617700622

Sedikides, C., Gaertner, L., \& Vevea, J. L. (2005). Pancultural self-enhancement reloaded: A meta-analytic reply to Heine (2005). Journal of Personality and Social Psychology, 89(4), 539-551. doi:10.1037/0022-3514.89.4.539

Sedikides, C., Ntoumanis, N., \& Sheldon, K. M. (2019). I am the chosen one: Narcissism in the backdrop of self-determination theory. Journal of Personality, 87(1), 70-81. doi: 10.1111/jopy.12402

Spain, S. M., Harms, P., \& LeBreton, J. M. (2014). The dark side of personality at work. Journal of Organizational Behaviour, 35, S41-S60. doi:10.1002/job.1894 
Spencer, L. M., \& Spencer, P. S. M. (2008). Competence at work models for superior performance. New York: John Wiley \& Sons.

Spurk, D., Keller, A. C., \& Hirschi, A. (2016). Do bad guys get ahead or fall behind? Relationships of the dark triad of personality with objective and subjective career success. Social psychological and personality science, 7(2), 113-121. doi:10.1177/1948550615609735

Stout, M. (2005). The ice people: living among us are people with no conscience, no emotions and no conception of love: Welcome to the chilling world of the sociopath. Psychology Today, 38(1), 72-76.

Veselka, L., Schermer, J. A., \& Vernon, P. A. (2012). The Dark Triad and an expanded framework of personality. Personality and Individual Differences, 53(4), 417-425. doi:10.1016/j.paid.2012.01.002

Viswesvaran, C., \& Ones, D. S. (2002). Agreements and disagreements on the role of general mental ability (GMA) in industrial, work, and organizational psychology. Human Performance, 15(1-2), 211-231. doi:10.1080/08959285.2002.9668092

Volmer, J., Koch, I. K., \& Göritz, A. S. (2016). The bright and dark sides of leaders' dark triad traits: Effects on subordinates' career success and well-being. Personality and Individual Differences, 101, 413-418. doi:10.1016/j.paid.2016.06.046

Wiersma, U. J., \& Kappe, R. (2017). Selecting for extroversion but rewarding for conscientiousness. European Journal of Work and Organizational Psychology, 26(2), 314-323. doi:10.1080/1359432X.2016.1266340

Wille, B., De Fruyt, F., \& De Clercq, B. (2013). Expanding and reconceptualizing aberrant personality at work: Validity of five-factor model aberrant personality tendencies to predict career outcomes. Personnel Psychology, 66(1), 173-223. doi:10.1111/peps.12016 
Young, S. M., \& Pinsky, D. (2006). Narcissism and celebrity. Journal of Research in Personality, 40(5), 463-471. doi:10.1016/j.jrp.2006.05.005

Yu, F., Peng, T., Peng, K., Tang, S., Chen, C. S., Qian, X., Chai, F. (2016). Cultural value shifting in pronoun use. Journal of Cross-Cultural Psychology, 47(2), 310-316. doi:10.1177/0022022115619230

Zeng, R., \& Greenfield, P. M. (2015). Cultural evolution over the last 40 years in China: Using the Google Ngram Viewer to study implications of social and political change for cultural values. International Journal of Psychology, 50(1), 47-55. doi:10.1002/ijop.12125

Zettler, I., \& Solga, M. (2013). Not enough of a 'dark’trait? Linking Machiavellianism to job performance. European Journal of Personality, 27(6), 545-554. doi: 10.1002/per.1912 

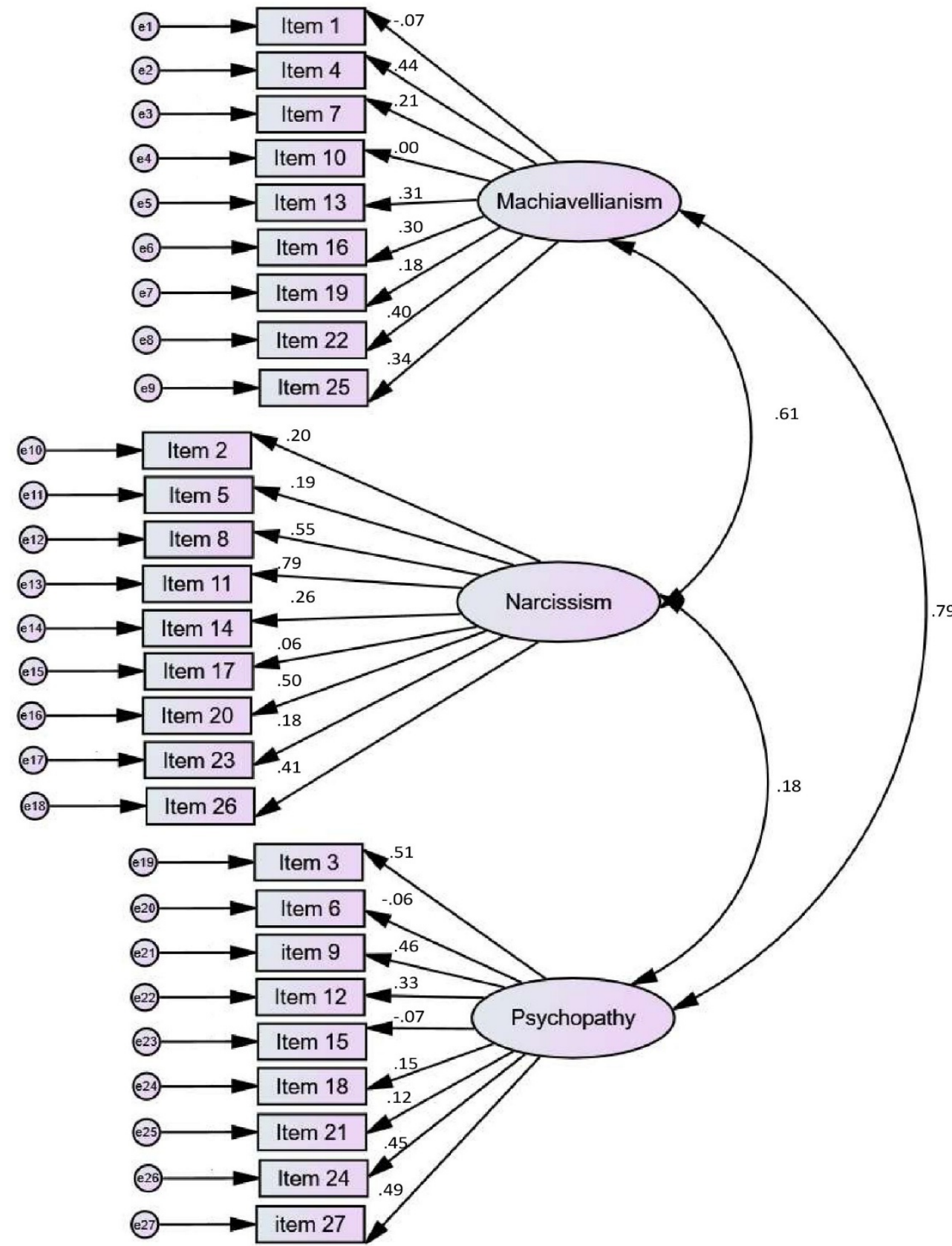

Figure 1. Confirmatory factor analysis of SD3 for Study 1. 

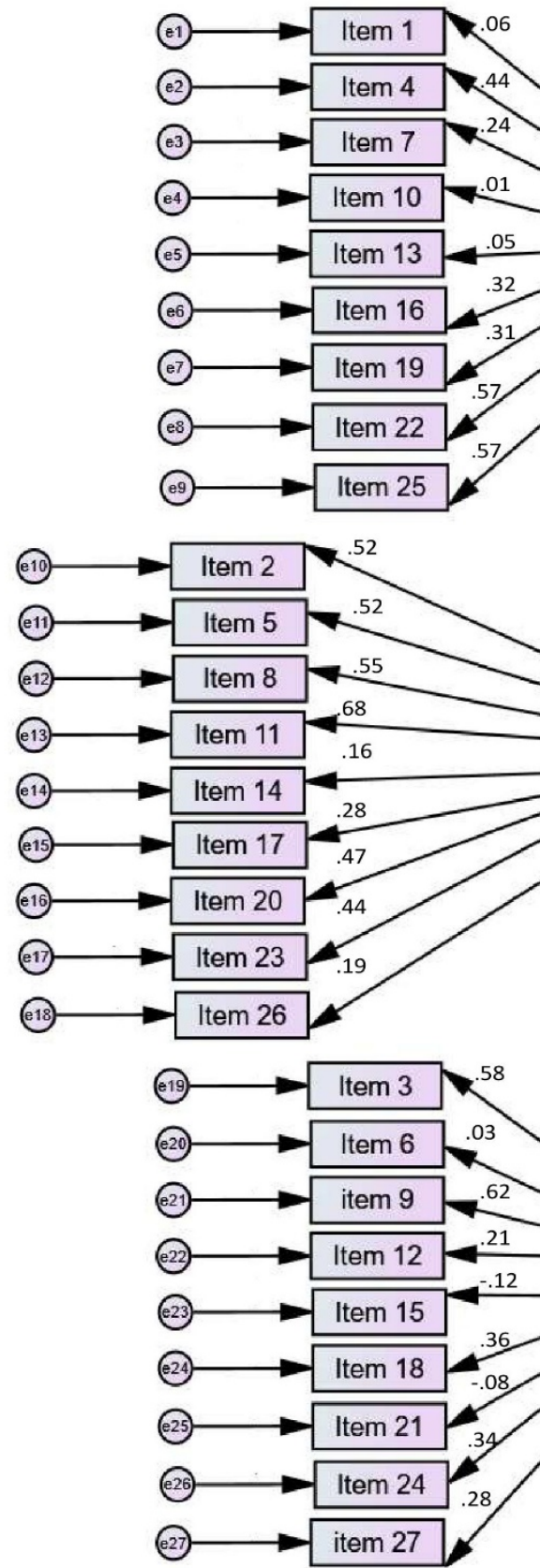

Figure 2. Confirmatory factor analysis of SD3 for Study 2. 